\title{
The food production chain and novel foods: introduction
}

\author{
Harry J. Wichers ${ }^{\#}$
}

The topic of this book, and also of this part on the food production chain and novel foods, was the development of strategies for better management of development and symptoms of allergies. This topic was chosen against the awareness that prevention is better than curing, and that much quality of life can be gained by such an approach. Also, considerable economic benefit may result, as the damage due to various allergies in the European Union in 1997 was valued at ca. $€ 30$ billion (UCB 1997). Extrapolating this figure to the price level of 2004, an estimate of $€ 40$ billion annually seems fair.

Food allergies have increased in incidence over the past decades. Although the reasons for this are not fully clear, a few important changes in our life style and consumption patterns may have influenced this increased occurrence (Midoro-Horiuti, Brooks and Goldblum 2001; Mills et al. 2001; Hoffmann-Sommergruber and Radauer 2003; Wichers et al. 2003):

- Environmental factors, such as pollution and changed in-house climate, may have promoted the development of allergies.

- Novel foods, containing proteins to which the population has not been exposed before, gain access to world markets at a, from a historical perspective, unrivalled pace.

- Recent research findings point at various levels of cross-reactivity between respiratory and food allergies (Mills et al. 2001; Sicherer 2001).

- There is a growing demand for foods that have a more fresh-like appearance; this quality criterion can be met by the development of imposing lower thermal burden for the conservation of foods; however, concomitantly, also potentially allergenic proteins retain more of their original structure due to this decreased thermal load, thus better retaining their allergenicity.

- Modern agricultural practice requires the use of less crop-protection agents. This goal is achieved via a.o. the development of more resistant crop cultivars. However, as many allergenic proteins have a defence-related biological function (Midoro-Horiuti, Brooks and Goldblum 2001), breeding for resistance may simultaneously imply breeding for more allergenic varieties.

A very promising perspective for better control and management of allergies is offered by an integral approach in the food production chain. Better quality raw materials, from an allergy perspective, for food production, together with better analytical tools and instruments for chain management, such as HACCP, and improved processing methods hold promise for a large group of allergic patients.

\footnotetext{
\# Agrotechnology and Food Innovations, Bornsesteeg 59, 6708 PD Wageningen, The Netherlands. E-mail: harry.wichers@wur.nl
} 
Fascinating and rapid developments in life sciences and in technological sciences offer many new openings for improvement of food quality from an allergy perspective. The rapidly developing genomics, proteomics and metabolomics disciplines allow us to deepen our insight into physical and biochemical parameters that are relevant for protein structure. This will allow us to compare the structure of allergens with varying stability at a molecular level, thus enabling us to draw conclusions on the parameters that determine this stability. It will allow us to identify specific proteolytic cleavage sites in food proteins, thus making the specific destruction of allergenic epitopes possible. It will teach us more about the relevance of the allergen matrix for its eventual stability and allergenicity.

Additionally, detailed knowledge on allergen protein structure will enable us to develop more sensitive and more specific assays (Wichers et al. 2003). It will also facilitate the improvement of the predictive value of in vitro assays for in vivo relevance, as we shall better understand which allergen elements are responsible for the provocation of allergenic symptoms.

The potential to influence our immunological response via the development of immunomodulatory food ingredients, for instance $\beta$-glucans and fungal immunomodulatory proteins from various edible mushrooms, is important not only from a perspective of allergy prevention, but probably also from a more generic perspective of development of functional food ingredients to improve the immune status of an aging population, as many chronic diseases are, causally or not, related to aberrations in our immune system (Kataoka et al. 2002; Hsieh et al. 2003).

Recent developments in food processing, such as high-pressure processing, pulsedelectric-field processing, combined physical and biochemical processing, but also traditional thermal processing, all hold promise for the development of hypoallergenic foods (Wichers et al. 2003 and references therein). Also the rapid developments in extraction and separation technology are very relevant for implication in the development of less allergenic foods.

An integral chain approach, in which the characteristics of raw materials are optimally tuned to the possibilities and perspectives of specific processing steps, is essential for the design of less allergenic foods, to improve the quality of life of many who are affected by a food allergy.

\section{References}

Hoffmann-Sommergruber, K. and Radauer, C., 2003. Bet v 1-homologous proteins. In: Mills, E.N.C. and Shewry, P.R. eds. Plant food allergens. Blackwell, Oxford, 125-140.

Hsieh, K.Y., Hsu, C.I., Lin, J.Y., et al., 2003. Oral administration of an ediblemushroom-derived protein inhibits the development of food-allergic reactions in mice. Clinical and Experimental Allergy, 33 (11), 1595-1602.

Kataoka, K., Muta, T., Yamazaki, S., et al., 2002. Activation of macrophages by linear (1right-arrow3)-beta-D-glucans. Impliations for the recognition of fungi by innate immunity. Journal of Biological Chemistry, 277 (39), 36825-36831.

Midoro-Horiuti, T., Brooks, E.G. and Goldblum, R.M., 2001. Pathogenesis-related proteins of plants as allergens. Annals of Allergy, Asthma \& Immunology, 87 (4), 261-271.

Mills, E.N.C., Madsen, C., Shewry, P., et al., 2001. Plant food allergens: the role of structure and function in allergenic potential. Food Allergy and Intolerance, 2, 194-209. 
Sicherer, S.H., 2001. Clinical implications of cross-reactive food allergens. Journal of Allergy and Clinical Immunology, 108 (6), 881-890.

UCB, 1997. European allergy white paper. The UCB Institute of Allergy. [http://www.theucbinstituteofallergy.ucb.be/WhitePaper/]

Wichers, H., Matser, A., Van Amerongen, A., et al., 2003. Monitoring of and technological effects on allergenicity of proteins in the food industry. In: Mills, E.N.C. and Shewry, P.R. eds. Plant food allergens. Blackwell, Oxford, 196-212. 